\title{
Modelling the learner model based ontology in adaptive learning environment
}

\author{
Saida Ulfa ${ }^{a, *}$, Deddy Barnabas Lasfeto ${ }^{\mathrm{b}}$, Citra Kurniawan ${ }^{\mathrm{c}}$ \\ ${ }^{a}$ State University of Malang (Indonesia) \\ ${ }^{b}$ State Polytechnic of Kupang (Indonesia) \\ ${ }^{c}$ Sekolah Tinggi Teknik Malang (Indonesia) \\ *)Corresponding author: saida.ulfa.fip@um.ac.id
}

\begin{abstract}
Currently, the online learners are increasingly demanding more personalized learning since the web technology, and the learners have individual features of characteristics such as learning goals, experiences, interests, personality traits, learning styles, learning activities, and prior knowledge. A personalized learning process requires an adaptive learning system (ALS). In order to adapt, a learner model is required. Thus, modelling the learner model in an adaptive system environment is a key point to success in recommending the learner. The ontology-based approach was used to model the adaptive learning model in this research. Ontology is a graph structure that consists of a collection of contexts, relationships, and models which related to contexts. The ontology of the learner model enables to produce a description of learner's properties which contains important information about domain knowledge, learning performance, interests, preference, goal, tasks, and personal traits.
\end{abstract}

Keywords: Personalized Learning, Adaptive Learning System, Ontology, Learner Model.

\section{Introduction}

The advancement of the digital age has led to the development of technology which covers almost all of the aspects of life. One aspect is education which takes an in the imperative role in human life. E-learning is distance learning that is done in a virtual way using the internet. In the e-learning system, users can learn at any time, anywhere and in any situation. In this system, the learning process does not require communication that is only in class. In this way, learners can apply movies, sound files with music, games and various types of content. One of the most important things in an E-learning system is adaptive learning with the level of knowledge, personality, and the ability of learner behaviour (Baishuang, et al. 2009). To reveal this, the system can provide information about users by building learner models (learning models). The learner model is a specific user model to display learners' special characters. In general, the 
learner model is a system of knowledge about learners. If there is information about the goals, abilities, background knowledge, interests and behaviour of participants, the system can adjust to learners.

The adaptive system is adopted based on the learner model; Therefore, the accuracy of adaptation depends on the correctness of the learner model. Also, in some cases, the learner model is used to assess learner knowledge. Therefore the modelling process is very important. Learner modelling helps the e-learning system to get learners' perceptions and recommend learning objects based on this perception. Personal learning processes and systems that support the process are called Adaptive Learning Systems (Wang, 2006; Winter, 2005). Therefore, the adaptive learning system can change its action to provide learning and environmental content or pedagogical methods for learners. The adaptive system is based on "learner's personal description" which is called the learner model. The process of gathering information to build learner models and updating is learner modeling. The adaptive system regulates learning material and teaching methods for learner models.

\section{Contribution}

The purpose of this study is to establish an ontological relationship between the formation of learner models with adaptive learning systems. The relationship that has been made is thoroughly investigated to test the suitability of the ontology model on the concept of relationship modelling of learners with an adaptive learning environment. The next goal is to identify the components of the characteristics of learners who can be the model variables of the learners. To verify the ontology relationship, what must be prepared is research related to the model of learners. Adaptive learning system and architectural development of learner models. The objectives that must be analyzed and completed are as follows:

a. How do learner models have to be compiled and modelled? Parameters for determining learner variables can be obtained from the ontology concept.

b. How do you build the ontology model of learner models in adaptive learning?

\section{Related Study}

The Learner Model contains learner characteristics that are important for adaptive learning. A typical learner model includes most of the important features of learners that influence learning, such as current knowledge, background, interests, goals, learning styles and preferences (Bunt \& Conati, 2003; Conati, Gertner, \& Vanlehn, 2002; Hense et .al., 2004; Díaz \& Gervás, 2005; Gauch, Speretta, Chandramouli, \& Micarelli, 2007). A flexible approach to learner modeling is 
presented in (Jeremic ', Jovanovic', \& b, 2012). This user model is used in DEPTHS (Design Pattern Teaching Help System), which is an intelligent learning guidance system for studying software design patterns. DEPTHS uses fuzzy rule-based knowledge assessment methods to update learner models during the learning process. Recent developments in semantic web technology have described the application of this technology to develop adaptive e-learning systems.

Several attempts have been made to implement an ontology-based education system, one of the most important components in this system is the learner model (Henze, Dolog, \& Nejdl, 2004; Jovanović, Gašević, \& Devedžić, 2009; El Mezouary, 2011). Ontology-based learning models express learner characteristics in an abstract way. However, this only expresses learner characteristics that are important to support system needs. For example, (Baishuang \& Wei, 2009) proposes a learner model for adaptive learning systems based on the Semantic Web.

Learning solely is not enough because learners eventually get bored with the heap of information received. Adaptive learning currently allows adaptation of pedagogical content to learning profiles to a certain extent where the parameters that distinguish them are detected in the learning process. These parameters include behavior, preferences, cognitive level and interaction (Behaz, et al. 2009; Yarandi, 2012). Every learner has his or her own way of learning which is his or her profile, and to encourage the development of knowledge, learners must consider the elements that really influence their learning. This model can only be realized with ontology involvement that fully participates in profile modeling and knowledge modeling (Fernández, et al. 1997). The ontology development process refers to what activities need to be done when building an ontology. However, the ontology development process does not imply the order of the implementation of these activities. The aim is to identify a list of activities that must be completed. Frequently, verbs are used to refer to such activities (Korchi, et al. 2015; Nguyen \& Do, 2008).

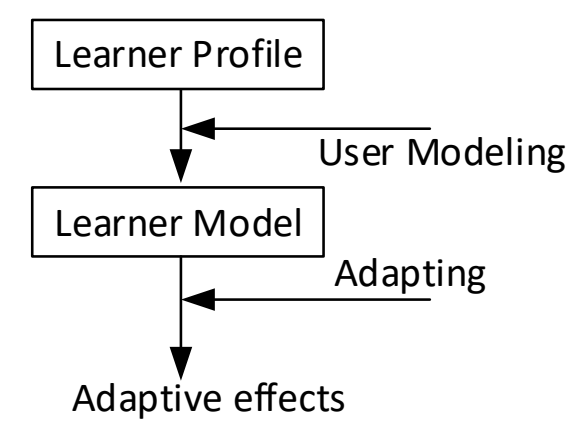

Figure 1. Adaptive Learning Model

To provide personalization in an e-learning with adaptive learning system, it is necessary to store learner characteristics (e.g. abilities, preferences, prior knowledge, and learning styles) in 
the learner model (Suryono, 2011; Vesin, 2011). On the other hand, dynamic features are updated during the learning process based on the interaction of learners with the system, for example, the values, abilities, and knowledge of learners. Learner modeling allows the system to personalize interactions between learners and the content learned. To achieve this goal, the system must predict the needs of learners based on information in the learning model to then offer content in ways that can be understood by learners. There are several techniques for modeling learners and enhancing this model. Ontology has proven to be an effective method for presenting knowledge in a particular domain by means of semantics (Snae \& Brueckner, 2007; Jeong, Choi, \& Song, 2012). Therefore, the author proposes an approach in which an ontological model is used to present the characteristics of learners. The ontology learning model presents personal preferences and learning characteristics of learners who interact with the system. This information is updated according to learner interaction with content. Updated information is used by adaptation models to make adaptation decisions.

\section{Learner Model Ontology}

In this section, the architecture for building learner models will be explained. General description of this architecture is shown in Figure 2. Information regarding learners is divided into two parts; personal information and behavioral information in online learning. The system uses two approaches to obtain learner personal information (Korchi, et al., 2017). On the other hand, with the results of the pretest taken from learners, the system can estimate the level of initial knowledge of learners from different backgrounds (Brut, et al. 2009). This estimation can be served as a reference to what learners need in terms of learning content. To obtain information on learner behavior, learner behavior during interaction with the e-learning system must be tracked. 


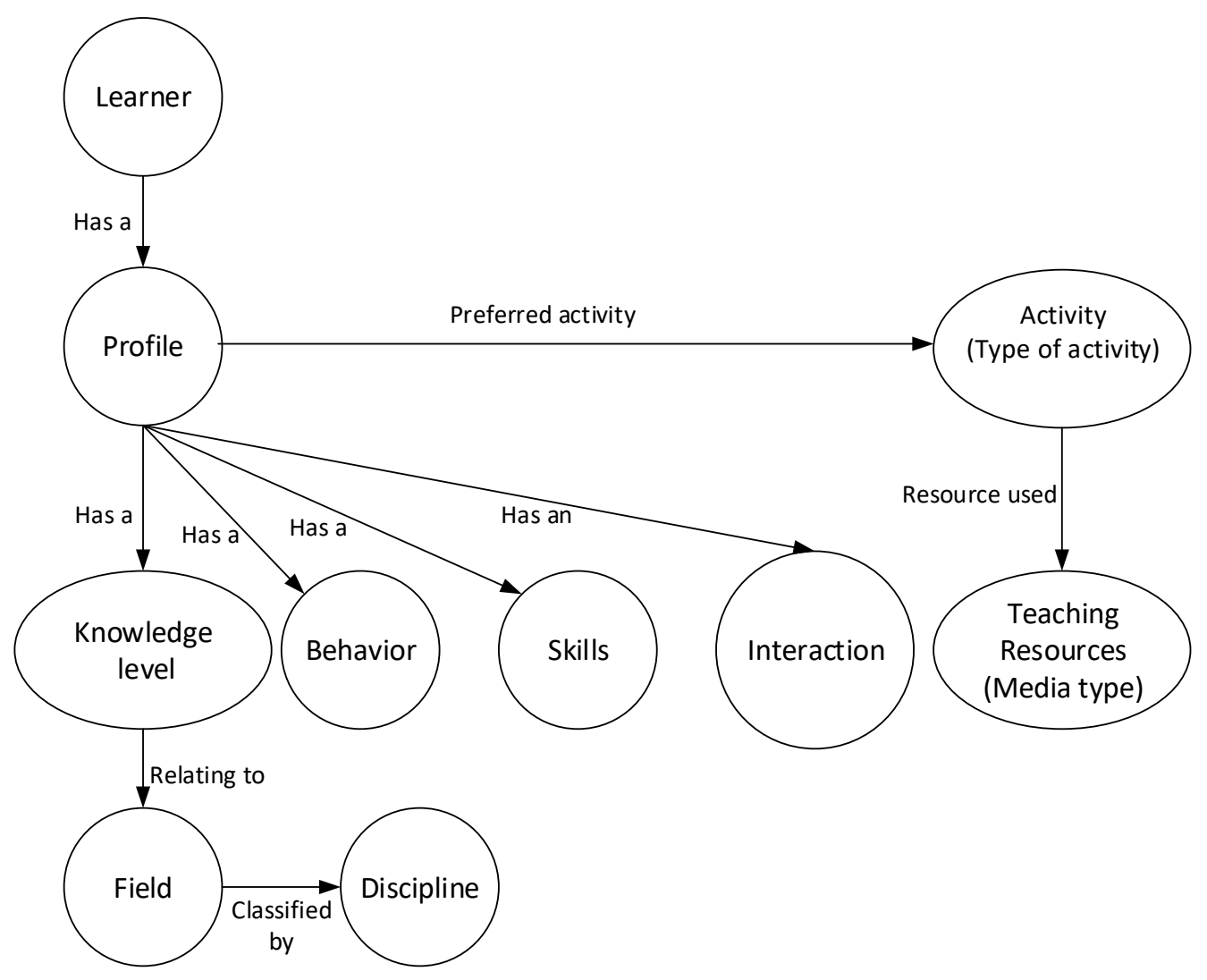

Figure 2. Learner Ontology

The ontology of learners begins with the identification of the profile models of each learner. The profile mode of learners comes from the knowledge level, behaviour, skills, and interaction. Each learner has unique and different characteristics in the learning process. Characteristics possessed by learners form a model called the learner model. The learner model consists of learner demographic information, learning style preferences, initial ability level and other information. The process of forming a profile model of learners consists of two stages, namely the initialization of the learner model and the renewal of the learner model. The process of initializing the model of learners begins with the learners following the pretest to find out their initial abilities, and from the results of these initial abilities, a classification of the ability levels of learners is made, namely the novice, intermediate and expert. The next process is the renewal of the learner model when learners have completed their activities, the process will be stored and recorded as information that can be traced back (Esichaikul, Lamnoi, \& Bechter, 2011). The development of learners in the learning process can shape and update the model of learners.

The learner model represents the characteristics of an individual or a group that has characteristic similarities. Model learners can be formed from profile models, cognitive overlays, predictive models and overlay courses (Castillo, Gama, \& Breda, 2008). The profile model 
contains all information related to learners such as name, learning style, age, and gender. Cognitive overlays record learners' knowledge and group it according to their level of ability such as beginners, intermediates and experts. Predictive models present learning resource preferences possessed by learners. Course overlays contain information relating to learner interactions with learning resources. Model learners can influence the learning process because each learner has different initial abilities.

The learner model is one component in adaptive learning, where the learner model is used to represent the knowledge possessed by the user (Dunwei et al., 2007). Adaptive Learning System (ALS) is a system that can dynamically adjust instructional content according to the characteristics of learners (Sanchez, Agudo, \& Rico, 2009). The AL monitors the activities of learners, preferences of learners and uses the results of their activities to update the status of the learners' models (Zhang, 2016). The learner model is used as initial data to facilitate the learning process. The ALS system can adapt by providing information content that is by the characteristics possessed by learners (Salahli, Özdemir, \& Yasar, 2013). When learners interact with the system, the first process is to create a user profile that contains demographic information from learners. The approach to creating participant profiles consists of three steps: a) Learners create their profiles based on interests and demographic data; b) The system updates learner profiles based on log files of activities that have been carried out by learners related to what interactions have been carried out with the system; c) Systems and learners complement each other's information; d) The system takes from external data such as profile data from other systems; e) Data that has been obtained is then processed into learner portfolio data. Portfolio data shows the level of progress shown by each learner's profile (Vagale \& Niedrite, 2012). Based on this, a basic algorithm is needed to develop learner models in ALS.

According to Bing et al. (2012). The algorithm for forming learner models consists of the level of knowledge, cognitive abilities and preferences of learners. The level of knowledge refers to the knowledge of learners to achieve goals. The level of knowledge $(\mathrm{k})$ refers to Bloom's taxonomy (h) about how cognitive roles such as knowledge, comprehension, application, analysis, synthesis and evaluation. Level "1" refers to knowledge (h1), level "2" refers to comprehension (h2), level "3" refers to application (h3), level "4" refers to analysis (h4), level "5" refers to synthesis (h5), and level "6" refers to evaluation (h6). As for learners with basic abilities are entered at the level of " 0 " (h0), so that the relationship is obtained as follows: Knowledge - How $(\mathrm{k}, \mathrm{h})=\{(\mathrm{k} 1, \mathrm{~h} 1),(\mathrm{k} 2, \mathrm{~h} 2), \ldots . . . .,(\mathrm{kn}, \mathrm{hn})\}$. Cognitive abilities are related to 
the ability of learners to complete tasks ranging from simple tasks to the most complex tasks. Cognitive ability can be described by describing the status of the ability level so that the relationship is obtained as follows: Ability - level $(a, 1)=\{(\mathrm{a} 1,11),\{(\mathrm{a} 2,12), \ldots$ where $\mathrm{a}$ is the cognitive ability, and 1 is the level of cognitive ability. Learner preferences are defined as interests, hobbies and other information in learning. In this case the preferences of learners are divided into learners' backgrounds (b1), learning strategies (b2), and study time (b3), represented as follows preferences $\mathrm{P}(\mathrm{c}, \sigma)=\{\langle\mathrm{b} 1, \sigma 1>,<\mathrm{b} 2, \sigma 2>,<\mathrm{b} 3, \sigma 3>\}$, where $\mathrm{c}$ is a concept, $\mathrm{b}$ is the preference of learners, and $\sigma$ is the coefficient that shows the level of concept preference (Jia, Yang, \& Zhang, 2012). The formation of model learners considers the interaction of learners with the system and characteristics of the system. Learner interaction (y) is illustrated in the

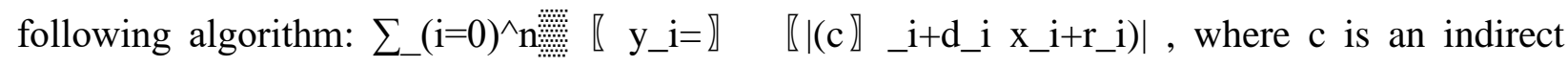
interaction, $\mathrm{d}$ is the impact of technology and $\mathrm{r}$ is a residual factor of system usage. The

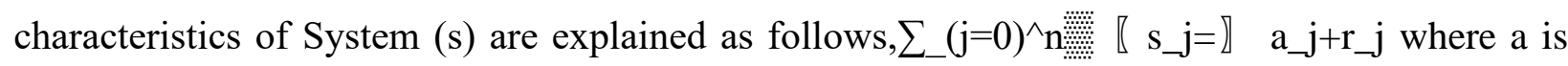
the number of system objects, so that overall the modeling of learners can be described in the

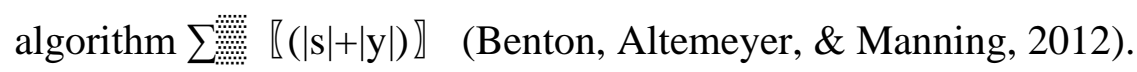

In assessing and considering learner characteristics, modeling is required in the profile. This assists to adapt pedagogical content to the needs of each learner to evaluate their skills, behavior, and interactions to generate new individual learning models (Jeremic, et al., 2012; Liu, 2009). Ontology in this modeling identifies learners' limitations, abilities, and gaps to begin learning situations that are appropriate to their cognitive level. This modeling process is shown in Figure. 3 which represents the proposed ontology and the various semantic links that connect concepts to sub-concepts (Brusilovsky, et al. 2005; Jeong, et. Al. 2015; Gauch, 2007; Korchi, et al., 2017 ). 


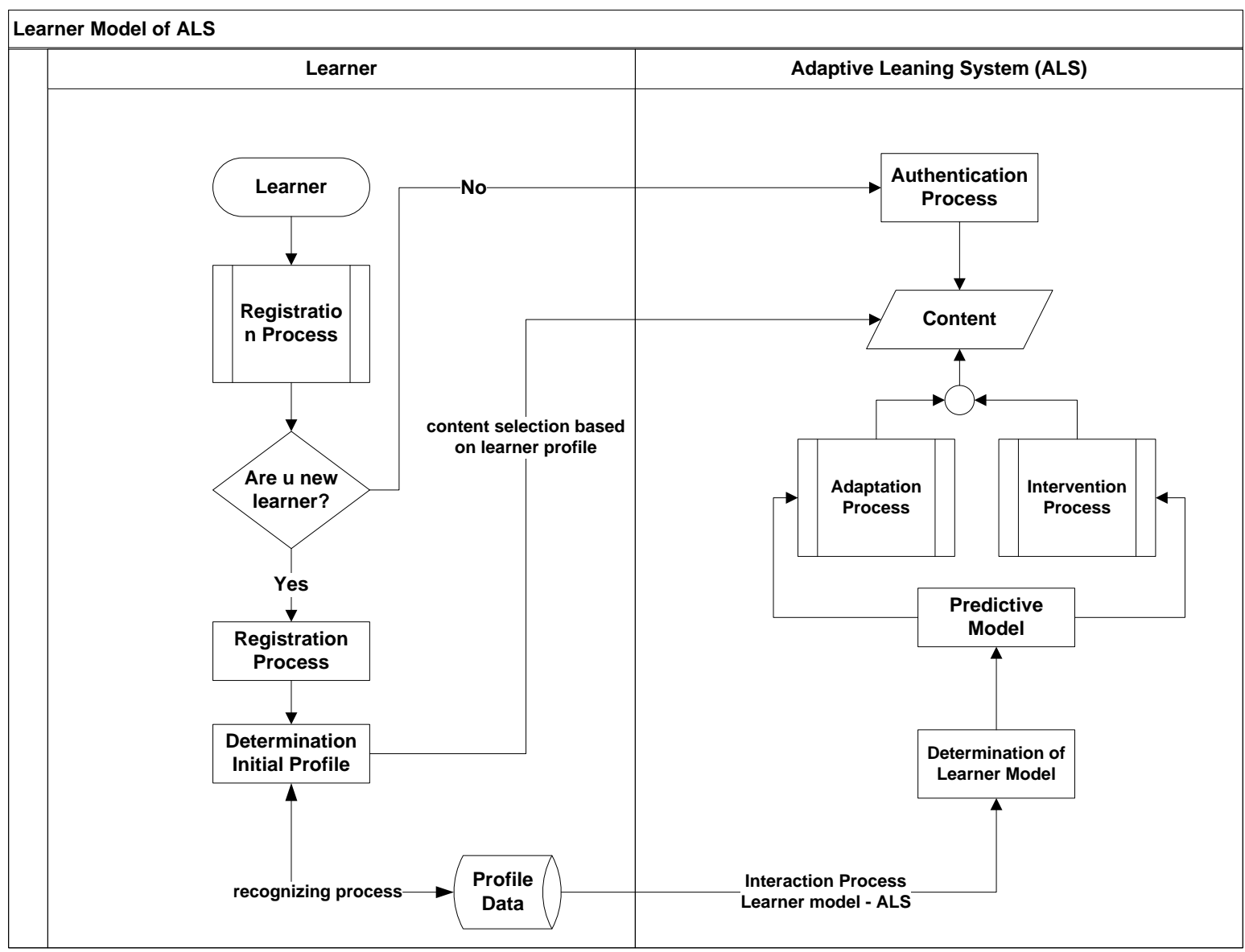

Figure 3. Course Ontology

The participant model consists of two stages, namely the model of students who have been formed during the learning process and new students who have a model based on the initial demographic info. Figure 3 show the ontology proposes that a modeling method consisting of several concepts that are semantically related to each other, namely:

a. Learners

Including personal data to be defined (for instance: Name, First Name, Age, Gender, Email,etc)

b. Profile:

This concept is related with the four other concepts which define learner, such as:

- Knowledge.

- Behavior.

- Interaction.

- Skill.

c. Learning Activities and Resources 
During learning activities related to learners, resources are functioned according to learner preferences in accordance with their profile. Ontology plays a role in the representation and organization of resources during the learning session.

d. Domain and Discipline

Ontology classifies various disciplines according to the field of knowledge. If the domain name is Science, then discipline can be in the form of Mathematics, Physics, or Natural Sciences. At the end of each learning session, the system has a set of information regarding learners that must be arranged and stored using an ontology to produce a new profile that will be taken into account in the next session. The system will interact intelligently with the learner dynamically adapting the subject to be presented to the learner in accordance with the results obtained and the learning mode that best suits the learner.

e. Authentification Process

Once the participant is connected to the learning platform, learner identity is stored, which will later allow the learner to find his or her workplace. Through this identity, the learner profile is associated with pedagogical activities to adjust it to the right profile.

\section{f. Learner's Profile Updating Process}

The update of the learner model consists of modifying values that represent the level of learner knowledge for a given number of resources from the concept given.

The learner profile is updated before or after the study session. Some techniques are used to update profiles, namely:

- Test level.

- Determination of learner interactions.

- Determination of behavior.

- The preferred type of material (learning content).

g. Interaction

Learner interaction with one of the proposed resources can determine the renewal of the profile. For instance, the length of time learners learns during reading a material content. The length of time will be determined by the time spent in this activity.

h. Behavior

Learner's behavior during the learning session determines profile detecting and updating.

i. History 
The learner model should store all relevant information about learners, including knowledge and attitudes (Brut, et al. 2009). The adaptive environment keeps all information about learners to be utilized at any time by the ontology. Learning records allow learners to know their background.

\section{Conclusion}

Ontology in learner modeling and adjustment of learning processes work by considering learner profiles. The contribution of the ontology model focuses on the following elements: behavioral analysis and evaluation, detection of learning styles, development of learner profiles that take into account learners' knowledge, preferences and attitudes. This ontology model can realize an adaptive learning system that allows the adaptation of pedagogical content according to current learner needs by evaluating the learner's self during the learning sequence. This ontology can detect more parameters, particularly with the contribution of the semantic Web to design better adaptive learning with more numbers of learners.

\section{References}

1. Asenova, A., \& Reiss, M. (2011). The role of visualization of biological knowledge in the formation of sets of educational skills. E-Learning University of Sovia, Bulgaria, 1, 1-9.

2. Awla, H. A. (2014). Learning styles and their relation to teaching styles. International Journal of Language and Linguistics, 2(3), 241-245. https://doi.org/10.11648/j.ijl1.20140203.23

3. Baukal, C. E., \& Ausburn, L. J. (2014). Learning strategy and verbal-visual preferences for mechanical engineering students. American Society for Engineering Education, 121.

4. Brunsting, S., De Best-Waldhober, M., Brouwer, A. S., Riesch, H., \& Reiner, D. (2013). Communicating CCS: Effects of text-only and text-and-visual depictions of CO2 storage on risk perceptions and attitudes. Energy Procedia, 37(0), 7318-7326. https://doi.org/10.1016/j.egypro.2013.06.670

5. Campos, A., Lopez, A., Gonzales, M. A., \& Amor, A. (2004). Imagery factors in the Spanish version of the verbalizer-visualizer questionnaire. Psychologist Reports, 94, 1149-1154.

6. Contero, M. (2004). Improving Visualization Skills in Engineering Education. Polytechnic University of Valencia and Cartagena, Jaume I and La Laguna universities.

7. Davis, S. E. (2007). Learning Styles and Memory. Institute for Learning Styles Journal, 1, $46-51$. 
8. Fayombo, G. (2015). Learning Styles, Teaching Strategies and Academic Achievement among some Psychology Undergraduates in Barbados. Caribbean Educational Research Journal, 3(2), 46-61.

9. Gilakjani, A. P. (2011). The Effect of Visual, Auditory, and Kinaesthetic Learning Styles on Language Teaching. International Conference on Social Science and Humanity, 5, 469-472.

10. Graf, S., Viola, S. R., \& Leo, T. (2007). In-Depth Analysis of the Felder-Silverman Learning Style Dimensions. International Society for Technology in Education, 40(1), 79-93.

11. Incorpora, C., Sala, G., Oliveri, S., Antonietti, A., Risoli, A., Carlo, D., ... Nascente, M. (2012). Verbalizer-Visualizer Style in Brain-lesioned Patients: Does Rehabilitation Matter? Review of Psychology Frontier, 1(1), 33-37.

12. Januchta, M. K., Hoffler, T., Thoma, G.-B., Prechtl, H., \& Leutner, D. (2017). Visualizers versus verbalizers: Effects of cognitive style on learning with texts and pictures - An eye-tracking study Computers in Human Behavior. Computers in Human Behavior, 68(March), 170-179. https://doi.org/10.1016/j.chb.2016.11.028

13. Kazu, I. Y. (2009). The Effect of Learning Styles on Education and the Teaching Process. Journal of Social Sciences, 5(2), 85-94.

14. Kirby, J. R., Moore, P. J., \& Schofield, N. J. (1988). Verbal and visual learning styles. Contemporary Educational Psychology, 13(May 2014), 169-184. https://doi.org/10.1016/0361-476X(88)90017-3

15. Kolekar, S. V, Pai, R. M., \& Pai, M. (2017). Prediction of Learner's Profile Based on Learning Styles in Adaptive E-learning System. IJET, 12(6), 31-51.

16. Litzinger, T. a., Lee, S. H., Wise, J. C., \& Felder, R. M. (2007). A Psychometric Study of the Index of Learning Styles. Journal of Engineering Education, 96(4), 309-319. https://doi.org/10.1002/j.2168-9830.2007.tb00941.x

17. McEwan, R. ., \& Reynolds, S. (2007). Verbalisers and Visualisers : Cognitive Styles That Are Less Than Equal. FIRST: Fanshawe Innovation, Research, Scholarship, Teaching, 13.

18. Mendelson, A. L., \& Thorson, E. (2004). How verbalizers and visualizers process the newspaper environment. Journal of Communication, 54(3), 474-491. https://doi.org/10.1093/joc/54.3.474

19. Palermo, L., Nori, R., Piccardi, L., Zeri, F., Babino, A., Giusberti, F., \& Guariglia, C. (2013). Refractive Errors Affect the Vividness of Visual Mental Images. PLoS ONE, 8(6). https://doi.org/10.1371/journal.pone.0065161 
20. Peterson, M. O. (2016). Schemes for integrating text and image in the science textbook: Effects on comprehension and situational interest. International Journal of Environmental and Science Education, 11(6), 1365-1385. https://doi.org/10.12973/ijese.2016.352a

21. Plass, J. L., Chun, D. M., Mayer, R. E., \& Leutner, D. (1998). Supporting visual and verbal learning preferences in a second-language multimedia learning environment. Journal of Educational Psychology, 90(1), 25-36. https://doi.org/10.1037/00220663.90.1.25

22. Richardson, A. (1977). Verbalizer-Visualizer: A Cognitive Style Dimension. Journal of Mental Imagery, 1, 109-126.

23. Spoltore, J. D., \& Smock, D. J. (1983). The Verbalizer-Visualizer Questionnaire: Additional Normative Data. Perceptual and Motor Skills, 56.

24. Stevens, M. J., Rapp, B. J., Pfost, K. S., \& Johnson, J. J. (1986). Further Evidence Of The Stability Of The Verbalizer-Visualizer Questionnaire. Perceptual and Motor Skills, 62, 301-302.

25. University of Bradford. (2014). Index of Learning Styles ( ILS ) Learning Style Questionnaire. Retrieved from www.brad.ac.uk/academic-skills/\%0A1

26. Wang, J., \& Mendori, T. (2015). The Reliability and Validity of Felder- Silverman Index of Learning Styles in Mandarin Version. Information Engineering Express. International Institute of Applied Informatics, 1(3), 1-8.

27. Wright, S., \& Stokes, A. (2015). The application of VARK learning styles in introductory level economics units. Issues in Educational Research, 25(1), 62-79. Retrieved from http://www.iier.org.au/iier25/wright.html

28. Zarei, S., Roohani, A., \& Jafarpour, A. A. (2015). The Effect of Visual / Verbal Learning Style on Reading Comprehension. International Journal of Educational Investigations, 2(6), 10-19. 